\title{
Tethered Cord Syndrome After Myelomeningocele Repair: A Literature Update
}

Leopoldo Mandic Ferreira Furtado ${ }^{1}$, José Aloysio Da Costa Val Filho ${ }^{1}$, François Dantas ${ }^{1}$, Camila Moura de Sousa ${ }^{1}$

1. Pediatric Neurosurgery, Vila da Serra Hospital, Nova Lima, BRA

Corresponding author: Leopoldo Mandic Ferreira Furtado, lmandicster@gmail.com

\section{Abstract}

Tethered cord syndrome (TCS) after myelomeningocele (MMC) repair (or secondary TCS) is a challenging condition characterized by neurological, orthopedic, and urological symptoms, which are combined with a low-lying position of the conus medullaris and damage to the stretched spinal cord owing to metabolic and vascular derangements. It has been reported that this syndrome affects, on average, $30 \%$ of children with MMC. In this review, we revisit the historical aspects of secondary TCS and highlight the most important concepts of diagnosis, treatment, and outcomes for secondary TCS as well as the current research regarding the impact of fetal MMC repair in the incidence and management of TCS. In the future, the development of synthetic models of TCS could shorten the learning curve of pediatric neurosurgeons, and research into the cellular proapoptotic features and increased inflammation biomarkers associated with TCS will also improve the treatment of this condition and minimize retethering of the spinal cord.

Categories: Neurosurgery

Keywords: tethered cord syndrome, secondary tethered cord syndrome, myelomeningocele, fetal surgery

\section{Introduction And Background}

Myelomeningocele (MMC) is an open neural tube defect that affects an average of three out of 10,000 live births, a statistic that is probably underestimated in developing countries; it is associated with high healthcare costs throughout a patient's lifespan [1-4]. MMC is morphologically characterized by a placode, zona epitheliosa, and junctional zone and is most commonly localized in the lumbar region. A placode is a non-neurulated spinal cord, and gets this name due to the formation of a plaque instead of the cylindric appearance of the neurulated spinal cord, and can be distinguished from surrounding tissue by its red color. Placodes are surrounded by abnormal vascularized tissue, known as zona epitheliosa, which is separated from the normal skin by the junctional zone.

Review began 09/19/2020 Review ended 10/08/2020 Published 10/14/2020

\section{(c) Copyright 2020}

Ferreira Furtado et al. This is an open access article distributed under the terms of the Creative Commons Attribution License CC-BY 4.0., which permits unrestricted use, distribution, and reproduction in any medium, provided the original author and source are credited.
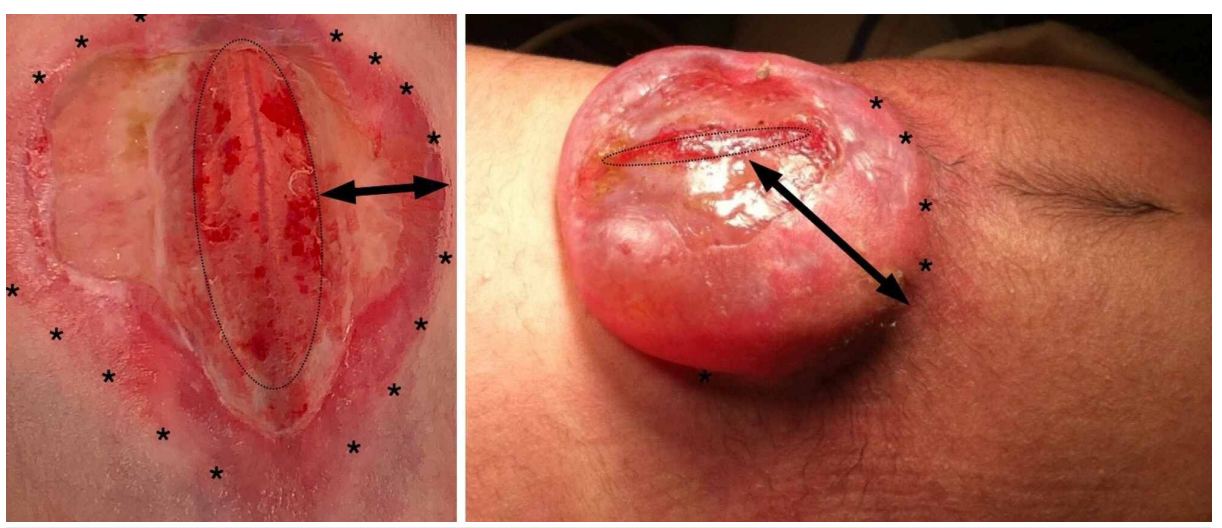

FIGURE 1: Anatomic landmarks of myelomeningocele

Two different anatomic presentations of MMC are depicted: in a plane fashion (left) or a saccular fashion (right). In both presentations, the placode is perceived as a non-neurulated spinal cord, seen in the red ellipsoid structure (delimitated by elliptical dot-points). The zona epitheliosa is the abnormal and poor vascular tissue surrounding the placode (double-headed black arrows), and the junctional zone (*) is the delimitation point of the normal skin and the zona epitheliosa

MMC: myelomeningocele

The classical MMC repair technique includes the separation of the placode from the zona epitheliosa, which is removed, and the placode is closed using a pial suture, promoting tunelization; this is followed by lateral 
exposition of the dura, which is sutured to covers the tunelized placode, and the normal skin is closed. At birth, the conus medullaris of MMC patients is below the normal anatomic level, usually at L1 or L2, which characterizes the anatomical tethered cord due to the attachment of the placode to the surrounding structures. During childhood growth, this attachment can lead to stretching of the spinal cord and becomes symptomatic in $30 \%$ of patients on average, who present with neurological, urological, and orthopedic issues [5]. This clinical condition is generally recognized as tethered cord syndrome (TCS) [6]. TCS is most commonly associated with thick filum terminale and other types of occult dysraphism as well as secondary scar formation after MMC repair [7]. Secondary TCS is the term used when the tethering occurs due to a primary surgical intervention, such as MMC. "Complex tethered cord” has been used synonymously with secondary TCS by Cochrane [8], Pierre-Kahn et al. [9], and Chapman [10], which highlights the anatomical challenges that surgical intervention represents.

The term "tethered spinal cord" was first coined in 1976 by Hoffman et al., who described 31 patients with elongated cords whose symptoms improved after sectioning of the filum terminale [11]. Nevertheless, other authors have also found an association between dysraphism and neurological symptoms [12,13]. Garceau coined the term "filum terminale syndrome" and reported a syndrome associated with a short, thick filum terminale, showing a short tau inversion recovery (STIR) signal. Furthermore, the surgical release of the abnormal filum resulted in the improvement of neurologic signs and the resolution of symptoms.

\section{Review}

\section{Pathophysiology}

Experimental studies with animal models have highlighted meaningful mechanisms related to the increase in spinal function impairment observed in TCS. The main aspects that have been studied are metabolism, blood flow, and extensibility. Laboratory findings have shown that inflammation and proapoptotic substances also play a role.

Yamada et al. $[6,14]$ performed an experimental study that determined the effect of tethering on the oxidative metabolism of cytochrome a/a3 using dual-wavelength reflection spectrophotometry and observed that untethering ameliorated the metabolism and that humans showed a similar reaction to untethering as cats. They considered some points of observation, such as the limitation of neurological deficits to the lumbosacral spinal cord due to the impairment of the oxidative metabolism found below the lowest pair of dentate ligaments (T12-L1). Nondermatomal sensory impairment associated with the gray matter is seriously affected by impaired oxidative metabolism. The conus medullaris displays the most affected oxidative metabolism impairment severity and the sphincteric outcome is also severe. Hypoxia has been identified as a factor of clinically relevant TCS, wherein the distraction of the spinal cord is thought to lead to vascular compromise with ischemic alterations occurring, especially in the gray matter [15]. Impaired movement of the spinal cord inside the spinal canal can also occur [16].

Previous studies have also elucidated the relationship between the elongation of the spinal cord under traction and the degree of metabolic dysfunction. In physiological conditions, the filum terminale, dentate ligaments, viscoelasticity of the spinal cord, and bulk of the lumbar spinal cord play a role in minimizing spinal cord injuries. According to concepts elucidated by experimental studies, the filum terminale and dentate ligaments work as buffers and, while the filum alleviates excessive elongation of the spinal cord by functioning as a rubber gun, the dentate ligaments give support to cervical, thoracic, and upper lumbar segments, counteracting the caudal traction force of the filum [7].

Another postulated mechanism has been attributed to the epipial layer of the spinal cord, which contains abundant collagen, and its extension narrows the cord and causes this layer to squeeze the interior of the cord, thus elevating intramedullary pressure with a "finger trap" effect. The cord becomes ischemic and metabolism ceases when the intramedullary pressure exceeds the perfusion pressure [17].

After MMC repair, features such as dysmorphic/misplaced placodio, shallow spinal canal, or absence of cerebrospinal fluid (CSF) around the placodio contribute to an increased probability of scar formation even when the surgeon has conducted correct dural closure $[16,18,19]$.

In fact, in current studies, these events have been classified as cellular and molecular alterations in MMC placodes, and it has been found that they exhibited significantly elevated levels of glial fibrillary acidic protein and vimentin-immunoreactivity compared to normal spinal cords. Additionally, chemokines and cytokines, crucial mediators of secondary lesion cascades after spinal cord injury, were found to be elevated at the mRNA and immunoreactivity levels [20]. Cohrs et al. studied specimens collected from 12 patients who underwent untethering and identified specific pro-inflammatory and proapoptotic mediators that could underlie secondary TCS after MMC repair. They hypothesized that preventing these lesion cascades by applying anti-inflammatory and antiapoptotic factors, coupled with a meticulous surgical technique, could improve the retethering rate [21].

\section{Epidemiology}


Several studies have reported that the incidence of symptomatic TCS after MMC repair varies widely, ranging from less than $10 \%$ of patients up to $30 \%$ [12,16,22-24]. Regarding patients who have undergone fetal repair of MMC, statistically insignificant higher rates of tethering, as well as a higher incidence of dermoid cysts, have been reported [2]. This fact could be explained by the better functional activity of these patients, facilitating the recognition of tethering symptoms. Non-separation of transitional skin during the fetal repair could explain the incidence of cysts due to the incorporation of unrecognized young tissues during fetal surgery [2].

Usually, a relationship exists between an increase in symptoms and childhood growth spurts due to the lengthening of the spinal canal, which yields progressive spinal cord injuries related to the metabolic, vascular, and mechanical variables considered by previous experimental studies. The most common age to observe this rise in symptoms is represented by two peaks of incidence according to some reports: one is observed between two and four years and the other is observed between the ages of eight and 10 years; however, one study reports only one period, which occurs between the ages of five and nine years [16,25-28].

\section{Clinical diagnosis}

Although all patients have observable anatomical alterations of the spinal cord, TCS is fundamentally a clinical syndrome in which patients present with progressive neurological, orthopedic, and urological symptoms. These symptoms include worsening of ambulation due to leg weakness and club feet, impairment of bladder and bowel functions, recurrent urinary infections, and impaired sensory function. In addition, back or leg pain associated with dermatomal distribution and spasticity is also frequently reported $[22,29,30]$. In recent research that comprised a Danish population, in 45 out of 166 patients with MMC who underwent untethering, the most common indications were progressive spine deformity (40\%), deteriorating ambulation (38\%), and deteriorating neurogenic bladder and/or bowel dysfunction (32\%) [31].

The possibility of shunt dysfunction mimicking symptoms of TCS can occur in MMC patients and the investigation of brain images is mandatory before the indication of spinal cord release. Sometimes, a shunt revision is indicated instead of untethering [16].

The assessment of patients by a multidisciplinary team consisting of orthopedists, physiotherapists, urologists, and neurosurgeons is paramount for the prompt recognition of TCS symptoms. Early diagnosis and treatment are essential to give patients the best possible chance of recovery. Furthermore, a delay in the diagnosis of secondary TCS is associated with irreversible injury [25,26,32].

\section{Radiological diagnosis}

MRI is the main imaging procedure used to evaluate the anatomic features of a tethered spinal cord [33]. Several features, including hydromyelia, scoliosis, and spinal cord adhesions, are related to the severity of the tethering process. Although many patients who undergo MMC repair present with a low conus position after image investigation, this does not always imply a tethered cord [24,34] (Figure 2). 


\section{Cureus}
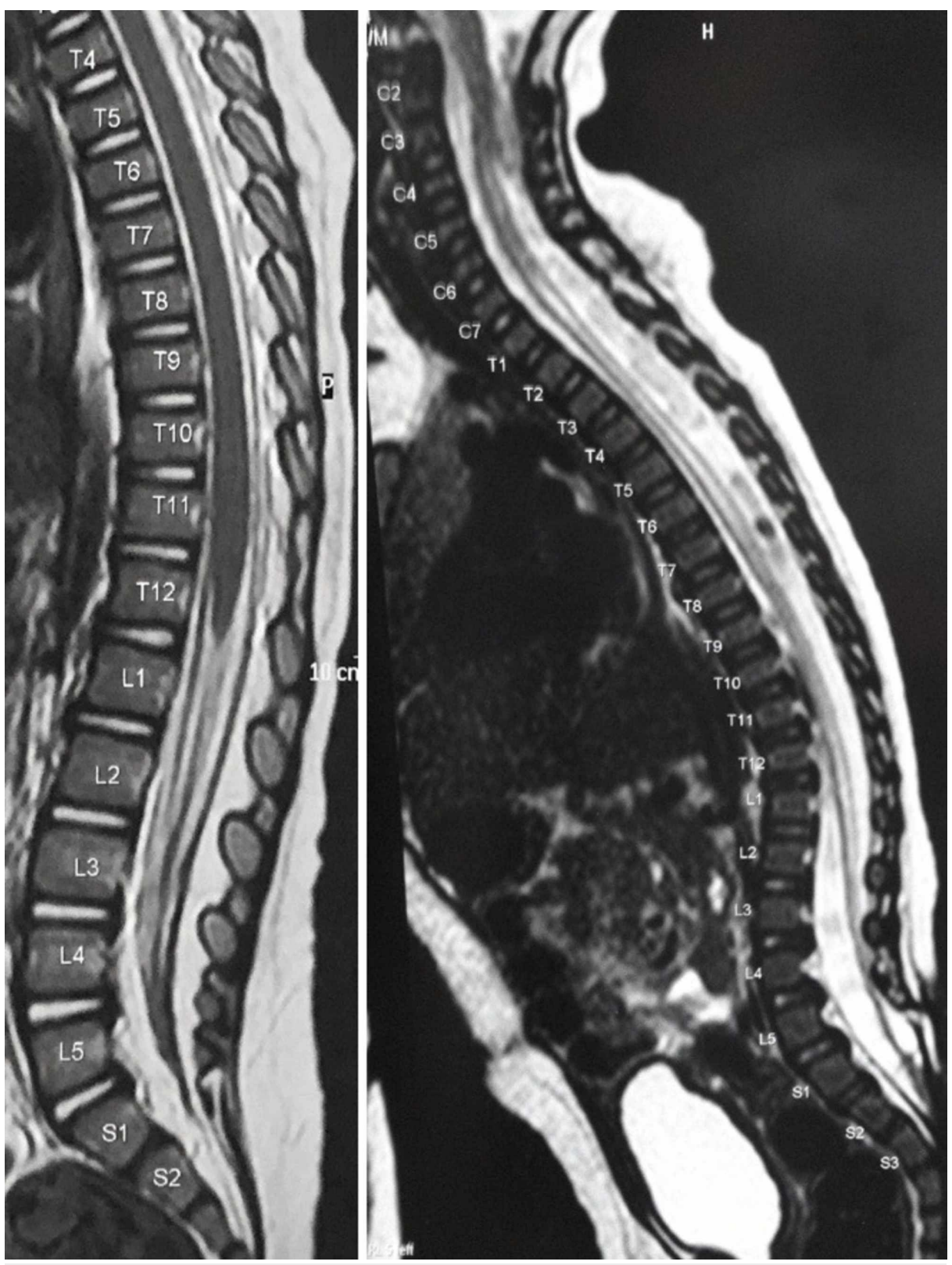

FIGURE 2: Normopositioning of conus medullaris and standard radiological findings of secondary tethered cord syndrome

Normopositioning of the conus medullaris at the level of T12 on a sagittal T2-weighted spinal MR image (left) and low-lying position of the conus medullaris at $\mathrm{S} 3$ in a four-month-old child who underwent post-natal MMC repair and had no clinical symptoms of tethered cord syndrome (right)

MMC: myelomeningocele

Taking this premise into account, Caldarelli et al. built a radiological scale based on the MRI imaging appearance of tethered cords and postulated four levels of tethering. Grade 1 implies a low-lying conus adherent to the lumbar scar, no evidence of adhesion along the spinal cord, and the conus medullaris is completely enveloped by the subarachnoid space. Grade II is featured by extensive adhesion of the placode and conus medullaris, with the placode incompletely enveloped by the subarachnoid space. In Grade III, there is abnormal tissue, such as lipoma or dermoid. Grade IV features severe kyphosis and/or scoliosis associated with features of Grade III [34]. Phase MRI of the longitudinal cord motions has offered some promise for predicting clinical tethering [35-37] (Figure 3). 


\section{Cureus}
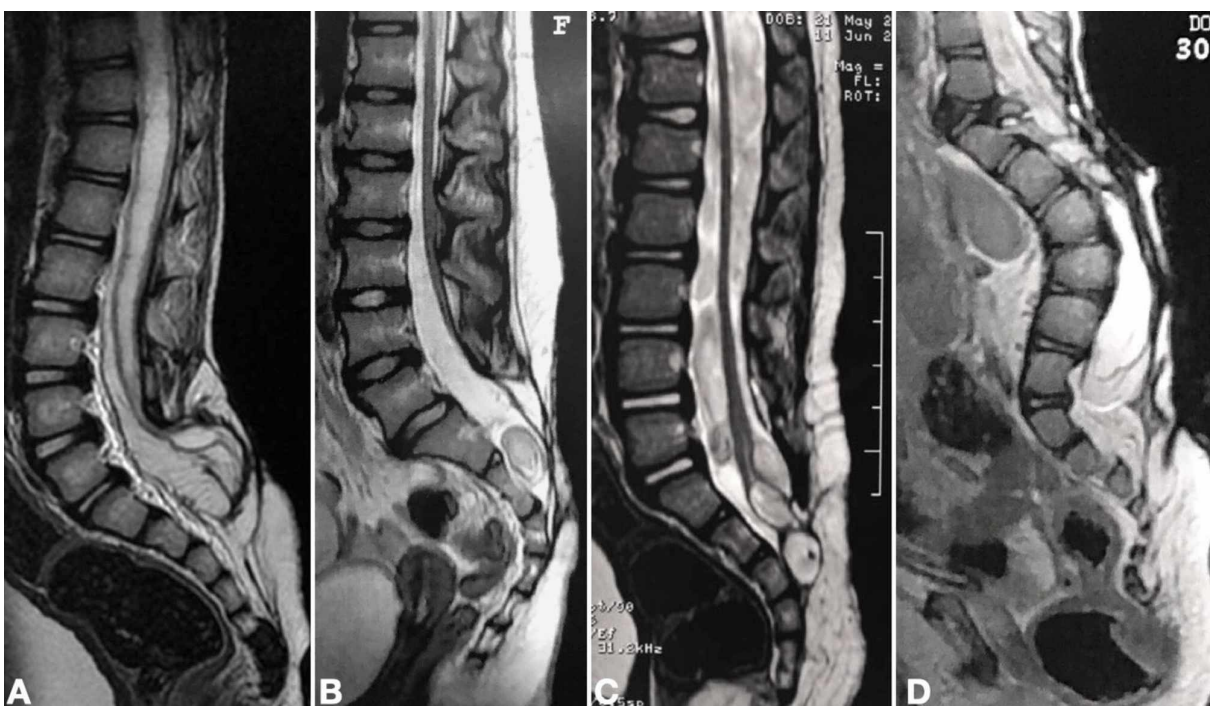

FIGURE 3: Features of several radiological tethering levels in children presenting with tethered cord syndrome after MMC repair

Sagittal T2-weighted spinal cord MR image displaying severe syringomyelia with a large adherence of placode, classified as grade II (A). Patients in B and C presented as grade III. Low conus position was associated with a dermoid cyst in an MMC repaired postnatally (B) or exhibited two intramedullary epidermoid cysts in a child who underwent fetal repair of MMC (C). Lumbar kyphosis is associated with a low conus in grade IV (D)

MMC: myelomeningocele

\section{The goals of untethering}

Multiple studies have demonstrated the benefits of untethering [17,22,25-27,38]. The main goal of surgical intervention for TCS is to mechanically interrupt the excessive tension of the attached spinal cord in symptomatic children, in which there is compromised metabolism and circulation of the spinal cord owing to spinal cord stretching. However, surgery does not always reverse or even stabilize neurologic deterioration, and spinal cord surgery also carries a risk of incurring neurologic injury and impairment of function [14]. Additionally, interrupting contact between the spinal cord and the tethering pathology allows for the free flow of CSF with no adhesions to prevent retethering [25,35,39-41].

\section{Strategies of surgical technique}

Surgery planning should consider the anatomical aspects, such as the positioning of the placode, its relationship with the skin, and the complexity of scarring. Although MRI provides the best information, the use of CT fused with MRI is also a valid option [42]. The use of previous functional scales could also help understand and quantify the achievements of patients after surgery [34].

Overall, untethering is challenging due to distorted anatomy and scarring from previous surgery. Scarring can contribute to an increase in the tension of neural structures at the site of surgical reconstruction (Figure 4) $[15,21,25]$.
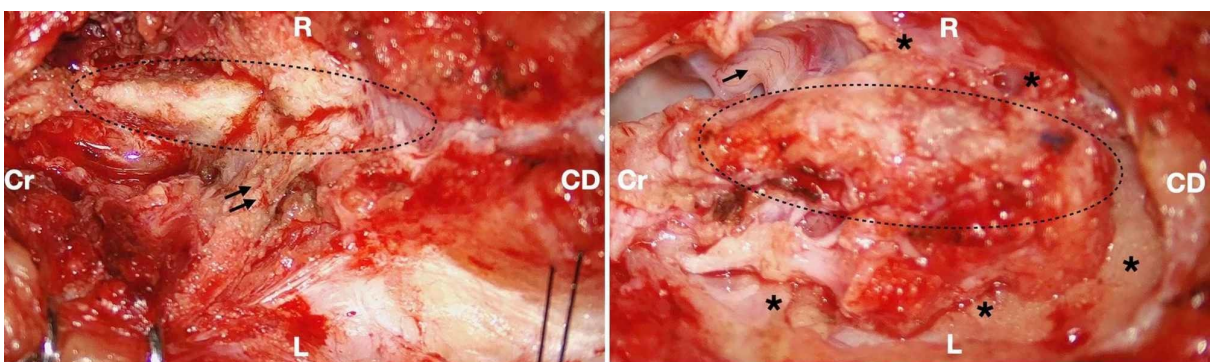

FIGURE 4: Microsurgical approach for tethered cord after MMC repair

The pictures depict two steps of untethering. At the beginning of the microsurgical approach, the placode (area limited by an ellipse) is exposed and thick scar tissue (double black arrows) is seen dorsally (left). After circumferential untethering is performed, the placodium (ellipse) is released on both sides and caudally $\left(^{*}\right)$. 
Ideally, the untethering should be approached from the upper level and should expose the normal cord in order to facilitate the progression of the dissection and recognition of the tethered region. Caution must be exercised to avoid damage to the placode attached to the scar tissue, and electrophysiological intraoperative monitoring should be conducted to determine the patient's level of functionality and to minimize additional neurological injuries during surgery [16]. Furthermore, this procedure should release the placode in all directions, according to the grading system proposed by Kirollos and Van Hille, who considered three levels of untethering [43].

Refinements of the surgical technique, including the use of microscopic view to perform dural sutures over the placodio and dural substitutes, could minimize CSF fluid leak and retethering $[19,40,44,45]$. However, there is currently no technique that can reliably prevent the tethering of the spinal cord after MMC repair [18]. Recurrent tethering may occur because the spinal canal in babies is shallow and the neural contents are in direct contact with the posterior dura, facilitating adhesion [19].

The occurrence of multiple-repeat tethered cord release was defined by Maher et al. [46] in patients who underwent at least two subsequent tethered cord releases after primary MMC repair. Al-Holou et al. [27] performed a comparative study among patients who underwent first retethering and multiple retethering and found no differences in outcomes.

\section{The role of electrophysiological intraoperative monitoring}

The goal of electrophysical intraoperative monitoring is to minimize the risk of spinal cord injury during untethering procedures [25]. Pouratian et al. evaluated a retrospective cohort of patients who underwent untethering with the guidance of intraoperative monitoring and found that, across 46 procedures, decisionmaking during surgery was influenced by intraoperative neurophysiological findings in $41 \%$ of cases [25]. They recommend transection of the so-called autonomous placode, which they define as a placode that has compound muscle action potential when stimulated with low current $(<10 \mathrm{~mA})$ in its caudal segment and no potential in the upper segments, after which they observed improvements in spasticity and lower back pain.

Electrophysiological monitoring of TCS of patients who underwent fetal MMC repair showed increased potentials even below the anatomic level of MMC repair, suggesting good functional outcomes for this population [47].

\section{Learning curve}

During training, neurosurgery residents face difficulties when learning about the operative technique regarding untethering due to the great heterogenicity of cases. Furthermore, the commitment not to harm the functional spinal cord is a concern. Sometimes, the recognition of anatomy depends on the neurosurgeon's experience.

The development of realistic simulations of congenital spine diseases is essential in order to shorten the learning curve of pediatric neurosurgeons. Efforts are currently underway to develop this kind of a model. Mattei et al. developed a synthetic model for pediatric spine pathologies, aiming to evaluate abilities such as recognition, duration of surgery, and the pressure used by the neurosurgeon [48].

\section{Complications and postoperative care}

Although the mortality rate associated with untethering is low, CSF leak followed by central nervous system infection is one of the most concerning side effects of untethering surgery and is reported in an average of $10-35 \%$ of cases [16]. This complication is associated with wound problems due to the absence of sufficient tissue to cover the placode and is linked to an increasing number of prior surgeries [46]. This could be addressed by planning with plastic surgeons in more complex cases. In our department, we recommend that the patient should remain flat for at least three days, and we use external lumbar drainage in order to minimize the risk of CSF leak and improve wound closure. In patients with CSF leakage, the initial treatment strategy is to maintain the patient in the plane decubitus position in order to minimize the CSF pressure under the skin as well as reinforcing sutures using sterile hydrocellular foam dressings. This kind of dressing precludes excessive manipulation and secondary infection of the skin. The reoperation is indicated only in cases where conservative measures have failed.

\section{Outcomes}

Concerning the main symptoms, such as pain, motor weakness, gait disturbances, scoliosis, and urinary disturbance, the majority of studies have reported an overall improvement or stabilization of symptoms, and 
increased importance has been attributed to an early diagnosis of TCS by a multidisciplinary team $[25,26,49]$. However, discrepancies in the percentage of overall improvement have been reported by some studies $[22,38]$, and improvement of pain ranges from $75 \%$ of cases to $90 \%$ [26, 27]. This fact could be explained by the heterogenicity of patients regarding the dependency of variable previous sensory functions.

In a historical retrospective series, Al-Holou et al. considered the outcomes in the first six months and four years after spinal cord release. They applied functional scales and observed an improvement in back pain mainly in older patients. The worst outcomes were observed in patients who underwent prophylactic untethering for scoliotic fusion. Furthermore, motor function was shown to be improved in $7 \%$ of patients, and stabilization was seen in $88 \%$ of patients in the first six months. On extended follow-up, this rate changed to $68 \%$ for stabilization and $6 \%$ for gaining better motor function. They also found no statistical differences among patients who achieved complete circumferential untethering compared to those who did not [27].

Scoliosis is reported in $80 \%$ of secondary TCS patients. According to McLone et al., the relationship of cause and effect between TCS and scoliosis is indirect. They found that untethering stabilized or improved the curve in most children with curves under $50^{\circ}$, and they observed stabilization beyond one year in $63 \%$ of cases [50].

Herman et al. [26] reported on 153 patients who underwent secondary tethered cord release and 100 patients post-MMC repair. At an average of four years of follow-up postoperatively, motor discomfort improved by $63 \%$, gait improved by $69 \%$, and bladder function improved in $35 \%$ of cases. They attributed an important role to urology following urodynamic tests in the early diagnosis of bladder compromise to achieve better results for detethering.

\section{Conclusions}

TCS is a clinical syndrome and its recognition must be prompt and early in order to increase the chances of better results. Patients who undergo fetal repair of MMC have a higher incidence of tethered cord symptoms and inclusion cysts, evidence that supports increased functionality below the level of anatomical closure. The best surgical approach to secondary TCS takes into account the features of spinal imaging and the use of intraoperative monitoring.

The development of synthetic models of TCS and research into cellular inflammation are some fronts of innovation to be improved for the treatment of tethered cord related to MMC.

\section{Additional Information \\ Disclosures}

Conflicts of interest: In compliance with the ICMJE uniform disclosure form, all authors declare the following: Payment/services info: All authors have declared that no financial support was received from any organization for the submitted work. Financial relationships: All authors have declared that they have no financial relationships at present or within the previous three years with any organizations that might have an interest in the submitted work. Other relationships: All authors have declared that there are no other relationships or activities that could appear to have influenced the submitted work.

\section{References}

1. Cavalheiro S, da Costa MDS, Moron AF, Leonard J: Comparison of prenatal and postnatal management of patients with myelomeningocele. Neurosurg Clin N Am. 2017, 28:439-448. 10.1016/j.nec.2017.02.005

2. Mazzola CA, Tyagi R, Assassi N, et.al: Congress of Neurological Surgeons systematic review and evidencebased guideline on the incidence of tethered cord syndrome in infants with myelomeningocele with prenatal versus postnatal repair. Neurosurgery. 2019, 85:E417-E419. 10.1093/neuros/nyz266

3. Kshettry VR, Kelly ML, Rosenbaum BP, Seicean A, Hwang L, Weil RJ: Myelomeningocele: surgical trends and predictors of outcome in the United States, 1988-2010. J Neurosurg Pediatr. 2014, 13:666-678. 10.3171/2014.3.PEDS13597

4. Agarwalla PK, Dunn IF, Scott RM, Smith ER: Tethered cord syndrome. Neurosurg Clin N Am. 2007, 18:531547. 10.1016/j.nec.2007.04.001

5. Perry VL, Albright AL, Adelson PD: Operative nuances of myelomeningocele closure. Neurosurgery. 2002, 51:719-723. 10.1227/00006123-200209000-00018

6. Yamada S, Zinke DE, Sanders D: Pathophysiology of "tethered cord syndrome" . J Neurosurg. 1981, 54:494503. 10.3171/jns.1981.54.4.0494

7. Tani S, Yamada S, Knighton RS: Extensibility of the lumbar and sacral cord. Pathophysiology of the tethered spinal cord in cats. J Neurosurg. 1987, 66:116-123. 10.3171/jns.1987.66.1.0116

8. Cochrane DD: Cord untethering for lipomyelomeningocele: expectation after surgery. Neurosurg Focus. 2007, 23:E9. 10.3171/FOC-07/08/E9

9. Pierre-Kahn A, Zerah M, Renier D, et.al: Congenital lumbosacral lipomas. Childs Nerv Syst. 1997, 13:298334. 10.1007/s003810050090

10. Chapman PH: Congenital intraspinal lipomas: anatomic considerations and surgical treatment. Childs Brain. 1982, 9:37-47. 10.1159/000120033 
11. Hoffman HJ, Hendrick EB, Humphreys RP: The tethered spinal cord: its protean manifestations, diagnosis and surgical correction. Childs Brain. 1976, 2:145-155. 10.1159/000119610

12. Hertzler DA 2nd, DePowell JJ, Stevenson CB, Mangano FT: Tethered cord syndrome: a review of the literature from embryology to adult presentation. Neurosurg Focus. 2010, 29:E1. 10.3171/2010.3.FOCUS1079

13. Garceau GJ: The filum terminale syndrome (the cord-traction syndrome) . J Bone Joint Surg Am. 1953, 35:711-716.

14. Yamada S, Won DJ, Yamada SM: Pathophysiology of tethered cord syndrome: correlation with symptomatology. Neurosurg Focus. 2004, 16:E6. 10.3171/foc.2004.16.2.7

15. Kang JK, Kim MC, Kim DS, Song JU: Effects of tethering on regional spinal cord blood flow and sensoryevoked potentials in growing cats. Childs Nerv Syst. 1987, 3:35-39. 10.1007/BF00707191

16. Caldarelli M, Boscarelli A, Massimi L: Recurrent tethered cord: radiological investigation and management . Childs Nerv Syst. 2013, 29:1601-1609. 10.1007/s00381-013-2150-4

17. Bowman RM, McLone DG: Tethered cord in children with spina bifida . Spina Bifida: Management and Outcome. Özek MM, Cinalli G, Maixner W (ed): Springer Science \& Business Media, Berlin, Germany; 2008. 1:267-274. 10.1007/978-88-470-0651-5_22

18. Hudgins RJ, Gilreath CL: Tethered spinal cord following repair of myelomeningocele . Neurosurg Focus. 2004, 16:E7. 10.3171/foc.2004.16.2.8

19. Zide B, Constantini S, Epstein FJ: Prevention of recurrent tethered spinal cord . Pediatr Neurosurg. 1995, 22:111-114. 10.1159/000120887

20. Kowitzke B, Cohrs G, Leuschner I, et.al: Cellular profiles and molecular mediators of lesion cascades in the placode in human open spinal neural tube defects. J Neuropathol Exp Neurol. 2016, 75:827-842. 10.1093/jnen/nlw057

21. Cohrs G, Drucks B, Sürie JP, Vokuhl C, Synowitz M, Held-Feindt J, Knerlich-Lukoschus F: Expression profiles of pro-inflammatory and pro-apoptotic mediators in secondary tethered cord syndrome after myelomeningocele repair surgery. Childs Nerv Syst. 2019, 35:315-328. 10.1007/s00381-018-3984-6

22. Bowman RM, McLone DG, Grant JA, Tomita T, Ito JA: Spina bifida outcome: a 25-year prospective. Pediatr Neurosurg. 2001, 34:114-120. 10.1159/000056005

23. Shurtleff DB, Duguay S, Duguay G, Moskowitz D, Weinberger E, Roberts T, Loeser J: Epidemiology of tethered cord with meningomyelocele. Eur J Pediatr Surg. 1997, 7:7-11. 10.1055/s-2008-1071200

24. Balasubramaniam C, Laurent JP, McCluggage C, Oshman D, Cheek WR: Tethered-cord syndrome after repair of meningomyelocele. Childs Nerv Syst. 1990, 6:208-211. 10.1007/BF01850974

25. Pouratian N, Elias WJ, Jane JA Jr, Phillips LH 2nd, Jane JA Sr: Electrophysiologically guided untethering of secondary tethered spinal cord syndrome. Neurosurg Focus. 2010, 29:E3. 10.3171/2010.3.FOCUS09299

26. Herman JM, McLone DG, Storrs BB, Dauser RC: Analysis of 153 patients with myelomeningocele or spinal lipoma reoperated upon for a tethered cord. Presentation, management and outcome. Pediatr Neurosurg. 1993, 19:243-249. 10.1159/000120739

27. Al-Holou WN, Muraszko KM, Garton HJ, Buchman SR, Maher CO: The outcome of tethered cord release in secondary and multiple repeat tethered cord syndrome. J Neurosurg Pediatr. 2009, 4:28-36. 10.3171/2009.2.PEDS08339

28. Dias MS: Neurosurgical management of myelomeningocele (spina bifida) . Pediatr Rev. 2005, 26:50-60. 10.1542/pir.26-2-50

29. Dias MS: Neurosurgical causes of scoliosis in patients with myelomeningocele: an evidence-based literature review. J Neurosurg. 2005, 103:24-35. 10.3171/ped.2005.103.1.0024

30. Tarcan T, Onol FF, Ilker Y, Simsek F, Ozek M: Does surgical release of secondary spinal cord tethering improve the prognosis of neurogenic bladder in children with myelomeningocele?. J Urol. 2006, 176:16011606. 10.1016/j.juro.2006.06.036

31. Borgstedt-Bakke JH, Wichmann TO, Gudmundsdottir G, Rasmussen MM: The incidence and effect of tethered cord release for tethered cord syndrome in patients with myelomeningocele: a population-based study (Epub ahead of print). J Neurosurg Pediatr. 2020, 1-6. 10.3171/2020.4.PEDS19722

32. Phuong LK, Schoeberl KA, Raffel C: Natural history of tethered cord in patients with meningomyelocele . Neurosurgery. 2002, 50:989-993. 10.1097/00006123-200205000-00011

33. Hall WA, Albright AL, Brunberg JA: Diagnosis of tethered cords by magnetic resonance imaging . Surg Neurol. 1988, 30:60-64. 10.1016/0090-3019(88)90181-4

34. Caldarelli M, Di Rocco C, Colosimo C Jr, Fariello G, Di Gennaro M: Surgical treatment of late neurological deterioration in children with myelodysplasia. Acta Neurochir (Wien). 1995, 137:199-206. 10.1007/BF02187194

35. Johnson DL, Levy LM: Predicting outcome in the tethered cord syndrome: a study of cord motion . Pediatr Neurosurg. 1995, 22:115-119. 10.1159/000120888

36. Levy LM, Di Chiro G, McCullough DC, Dwyer AJ, Johnson DL, Yang SS: Fixed spinal cord: diagnosis with MR imaging. Radiology. 1988, 169:773-778. 10.1148/radiology.169.3.3186999

37. McCullough DC, Levy LM, DiChiro G, Johnson DL: Toward the prediction of neurological injury from tethered spinal cord: investigation of cord motion with magnetic resonance. Pediatr Neurosurg. 1990, 16:37. $10.1159 / 000120494$

38. Haberl H, Tallen G, Michael T, Hoffmann KT, Benndorf G, Brock M: Surgical aspects and outcome of delayed tethered cord release. Zentralbl Neurochir. 2004, 65:161-167. 10.1055/s-2004-832347

39. Aliredjo RP, de Vries J, Menovsky T, Grotenhuis JA, Merx J: The use of Gore-Tex membrane for adhesion prevention in tethered spinal cord surgery: technical case reports. Neurosurgery. 1999, 44:674-677. 10.1097/00006123-199903000-00139

40. Samuels R, McGirt MJ, Attenello FJ, et.al: Incidence of symptomatic retethering after surgical management of pediatric tethered cord syndrome with or without duraplasty. Childs Nerv Syst. 2009, 25:1085-1089. 10.1007/s00381-009-0895-6

41. Linder M, Rosenstein J, Sklar FH: Functional improvement after spinal surgery for the dysraphic malformations. Neurosurgery. 1982, 11:622-624. 10.1227/00006123-198211000-00006

42. Bamba Y, Nonaka M, Nakajima S, Yamasaki M: Three-dimensional reconstructed computed tomography- 


\section{Cureus}

magnetic resonance fusion image-based preoperative planning for surgical procedures for spinal lipoma or tethered spinal cord after myelomeningocele repair. Neurol Med Chir (Tokyo). 2011, 51:397-402.

10.2176/nmc.51.397

43. Kirollos RW, Van Hille PT: Evaluation of surgery for the tethered cord syndrome using a new grading system. Br J Neurosurg. 1996, 10:253-260. 10.1080/02688699650040106

44. Tubbs RS, Oakes WJ: A simple method to deter retethering in patients with spinal dysraphism . Childs Nery Syst. 2006, 22:715-716. 10.1007/s00381-006-0051-5

45. Guthkelch AN, Pang D, Vries JK: Influence of closure technique on results in myelomeningocele . Childs Brain. 1981, 8:350-355. 10.1159/000119999

46. Maher CO, Goumnerova L, Madsen JR, Proctor M, Scott RM: Outcome following multiple repeated spinal cord untethering operations. J Neurosurg. 2007, 106:434-438. 10.3171/ped.2007.106.6.434

47. Jackson EM, Schwartz DM, Sestokas AK, et.al: Intraoperative neurophysiological monitoring in patients undergoing tethered cord surgery after fetal myelomeningocele repair. J Neurosurg Pediatr. 2014, 13:355361. 10.3171/2014.1.PEDS11336

48. Mattei TA, Frank C, Bailey J, et.al: Design of a synthetic simulator for pediatric lumbar spine pathologies . J Neurosurg Pediatr. 2013, 12:192-201. 10.3171/2013.4.PEDS12540

49. Schoenmakers MA, Gooskens RH, Gulmans VA, Hanlo PW, Vandertop WP, Uiterwaal CS, Helders PJ: Longterm outcome of neurosurgical untethering on neurosegmental motor and ambulation levels. Dev Med Child Neurol. 2003, 45:551-555. 10.1017/s0012162203001002

50. McLone DG, Herman JM, Gabrieli AP, Dias L: Tethered cord as a cause of scoliosis in children with a myelomeningocele. Pediatr Neurosurg. 1990, 16:8-13. 10.1159/000120495 